\title{
Characteristics of runoff pollution in a highly urbanized region: A case study in the Dongguan City
}

\author{
Qiming Liu ${ }^{1}$, Jingni Zeng ${ }^{1}$, Hongyan $\mathrm{Wu}^{1}$, Qiangqiang Rong ${ }^{1 *}$, Wencong Yue ${ }^{1}$, Meirong $\mathrm{Su}^{1}$ \\ ${ }^{1}$ Research Center for Eco-environmental Engineering, Dongguan University of Technology, Dongguan, Guangdong, 523808, China
}

\begin{abstract}
Urban runoff pollution has become one of the major sources of water pollution. Rapid urbanization process in China has led to a significant increase in the pollution loads, which has posed great threats on the regional water environmental safety. Thus, it is of great importance to systematically analyse the characteristics of runoff pollution in some typical highly urbanized regions. Taking the Dongguan City in South China as the study area, output and spatial characteristics of the pollution emissions were investigated through a GIS-based empirical model. The results showed that the annual pollution loads of chemical oxygen demand (COD), suspended solids (SS), total nitrogen (TN) and total phosphorus (TP) exported from the city were approximately 338489, 613175, 28292 and 2824 t/a, respectively. In particular, the Songshan Lake Area in the city had the largest pollution loads, while the Water Town New Area had the least. In terms of pollution export fluxes unit area, they were highest in the Central Downtown Area (i.e. 2124, 3450, $145 \mathrm{and} 16 \mathrm{~kg} / \mathrm{hm}^{2} \cdot \mathrm{a}$ for COD, SS, TN and TP, respectively) and relatively lower in the Southeastern Bordering Shenzhen Area. Enhancing the environmental management and improving the public environmental protection awareness are necessary for mitigating runoff pollution.
\end{abstract}

\section{Introduction}

Rapid urbanization leads to the conversion of natural underlying to impervious surfaces of a region. This change of landscape pattern causes increasing runoff volume and peak flow. Also, large amounts of pollutants are transported to drainage systems and downstream water bodies during rainfall events, causing severe runoff pollution [1]. Some research has shown that this pollution can lead to serious deterioration of urban water quality and greatly affect the health of both human beings and aquatic organisms [2]. It is of great importance to systematically analyse the characteristics of runoff pollution in some typical highly urbanized regions considering landscape patterns and rainfall events.

Previously, many researches have been conducted to quantify the loads of urban runoff pollution. Mean concentration methods, mechanism and statistical models are the three typical approaches. Specifically, mean concentration methods usually need simultaneous monitoring data of water quality and quantity of surface runoff. Mechanism models can provide information regarding the spatial and temporal distribution characteristics of runoff pollution loads [3-5]. However, large amounts of input data often limit the applications of these models. In addition, most mechanism models were developed for some specific regions. Hence, considering the differences in climate and soil characteristics among different research areas, it might be necessary to make some improvements when using these models $[6,7]$. On the contrary, statistical models have relatively simpler structures and require less data, which have been widely used in many regions. In particular, the calculation model proposed by Schueler (1987) was a very popular one, which has been proved to be effective in quantitively estimate the runoff loads in highly urbanized areas [8, 9]. However, these previous researches were mainly focus on providing the total amounts of runoff pollution loads. Spatial distribution of the pollution was rarely reflected.

Taking a typical urbanized area (i.e., the Dongguan City) in South China as the study area, the objective of this research is to proposed a GIS-based empirical model for urban runoff pollution estimation. Output and spatial characteristics of the pollution emissions from the city in 2020 will be systematically analysed. Results of this research will provide some basic information of pollution status. It is important for the regional NPS pollution control and water environmental planning and management. Also, the proposed method can provide a methodological reference for other urbanized areas with similar concerns.

\section{Materials and Methods}

\subsection{Input data and sources}

The input data employed for the runoff pollution load estimation includes areas of different land use types, precipitation amount, and the event mean concentrations (EMCs) of Chemical oxygen demand (COD), suspended

*Corresponding author's e-mail: rongqq@dgut.edu.cn 
solids (SS), total nitrogen (TN) and total phosphorus (TP) related to different land use types (Table 1). The area data of different land use types was obtained from GlobeLand 30 land cover dataset prepared by Ministry of Natural Resources of the People's Republic of China (http://www.globallandcover.com/). The precipitation data was obtained from Dongguan meteorological station. The EMCs were collected from relevant references $[10,11]$.

Table 1. EMC of different land use types in Dongguan $(\mathrm{mg} / \mathrm{L})$.

\begin{tabular}{ccccc}
\hline & COD & SS & TN & TP \\
\hline Arable land & 82 & 175 & 33.5 & 1.87 \\
Forest land & 4.5 & 193 & 3.12 & 0.14 \\
Grass land & 5.3 & 486 & 3.08 & 0.12 \\
Water & 5.3 & 486 & 3.08 & 0.12 \\
Construction land & 298.8 & 347.19 & 14.19 & 2.12 \\
\hline
\end{tabular}

\subsection{Characteristic analysis of urban runoff pollution load}

An empirical model proposed by Schueler was used in this research to estimate pollutant emissions. The model framework is shown as follows [8].

$$
\begin{gathered}
L t=\left[\left(C_{F}\right)(\psi)(A)(P)(C) 0.01\right] \\
\psi=0.05+0.009 \times I
\end{gathered}
$$

where $L t$ is the runoff discharge load within time period $t$ (kg); $C_{F}$ represents the proportion of rainfall events that generated runoff in the total rainfall events; $\psi$ is the average runoff coefficient of the runoff area ( $\mathrm{m}^{3}$ runoff/ $\mathrm{m}^{3}$ rainfall); $I$ is the impervious rate; $A$ is the runoff catchment area $\left(\mathrm{hm}^{2}\right) ; P$ is the precipitation amount within time period $t(\mathrm{~mm}) ; C$ is the weighted average concentration of pollutant runoff $(\mathrm{mg} / \mathrm{L}) ; 0.01$ is a unit conversion factor.

In this research, the Geographic Information System was coupled with the above method, leading to a GISbased empirical model for urban runoff pollution estimation. Through combining the area data of different land use types obtained from land cover dataset, the spatial distribution of runoff pollution load was derived.

\section{Case study}

The Dongguan city $\left(113^{\circ} 31^{\prime}-114^{\circ} 15^{\prime}\right.$ E, $\left.22^{\circ} 39^{\prime}-23^{\circ} 09^{\prime} \mathrm{N}\right)$ is located in the core area of the Guangdong-Hong KongMacao Greater Bay Area in South China. It is one of the largest manufacturing bases in the Guangdong Province. Construction land accounts for approximately $51 \%$ of the total area, followed by forest land $(23 \%)$, arable land $(14 \%)$, water (9\%) and grass land (3\%). According to the Statistical Bulletin on National Economic and Social Development of the Dongguan City in 2019, the regional GDP has achieved RMB 948.25 billion. However, the rapid economic development and urbanization process have significantly influenced the regional water environment. In particular, the contribution of urban runoff pollution has greatly increased in recent decades. Thus, research on the output and distribution characteristics of runoff pollution in this area is of great importance, which will provide some basic information for decision-making on water environmental management. According to the city planning document of the government, the research area was divided into 6 districts: Central Downtown Area (CDTA), Songshan Lake Area (SSLA), Southwestern Coastal Area (SWCA), Water Town New Area (WTNA), Eastern Industrial Park Area (EIPA) and Southeastern Bordering Shenzhen Area (SBSA) (Figure 1).

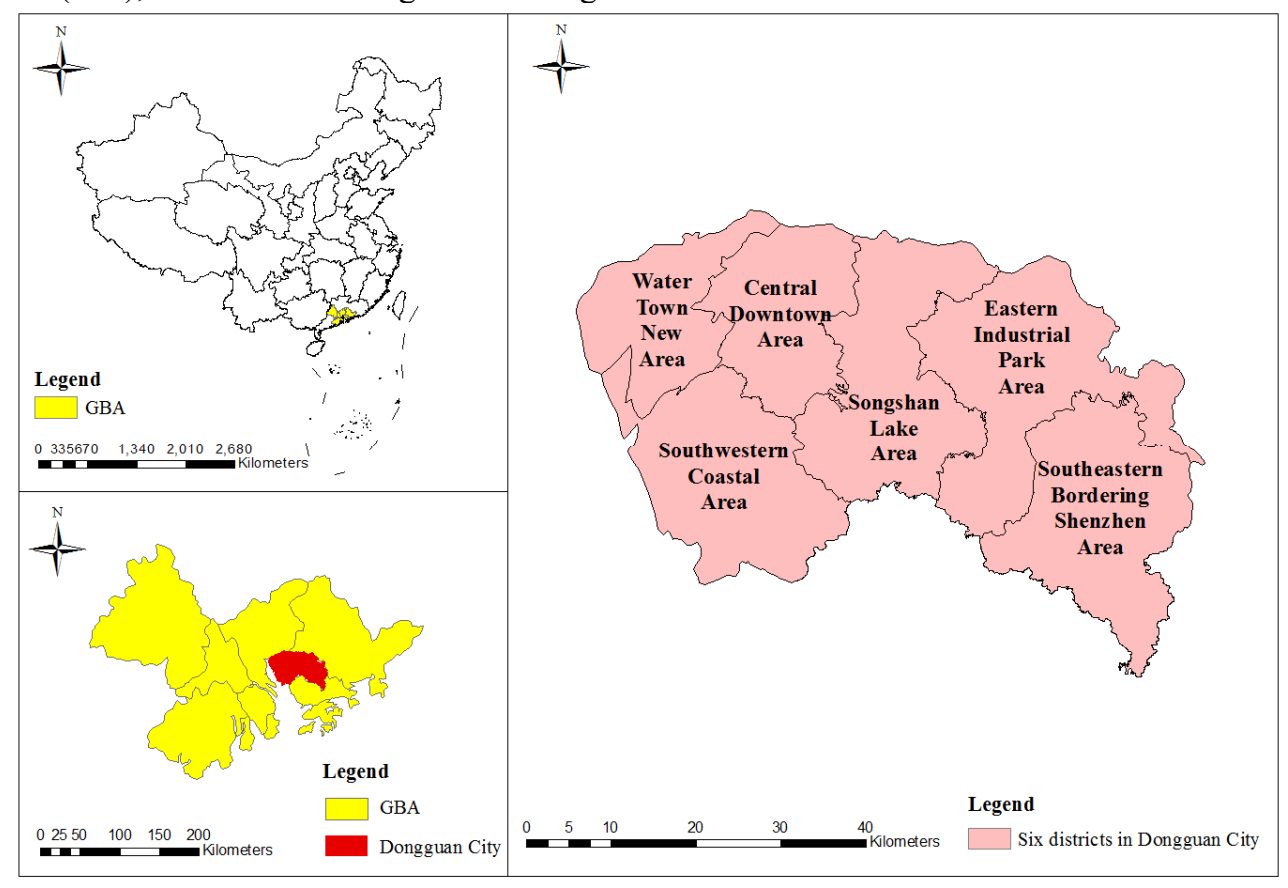

Figure 1. Location of study area. 


\section{Results and discussion}

The total annual loads of COD, SS, TN and TP were approximately 338489, 613175, 28292 and 2824 t/a, respectively. The Songshan Lake Area in the city had the largest pollution loads, while the Water Town New Area had the least (Table 2). The pollution export fluxes were the highest in the Central Downtown Area and relatively lower in the Southeastern Bordering Shenzhen Area (Figure 2).

Table 2. Total annual loads of runoff pollutants in the six districts $(\mathrm{t} / \mathrm{a})$.

\begin{tabular}{ccccc}
\hline & COD & SS & TN & TP \\
\hline CDTA & 61957 & 100607 & 4232 & 476 \\
SSLA & 75436 & 125845 & 6077 & 620 \\
SWCA & 62460 & 115851 & 5289 & 524 \\
WTNA & 33620 & 68897 & 3581 & 314 \\
EIPA & 63331 & 113942 & 5732 & 548 \\
SBSA & 41684 & 88033 & 3381 & 342 \\
\hline
\end{tabular}
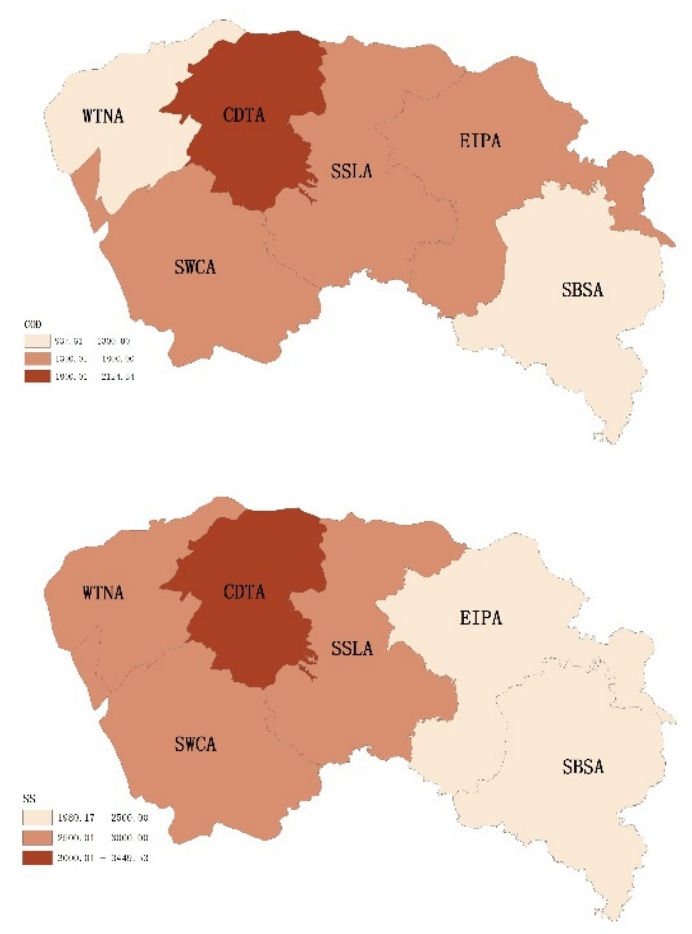
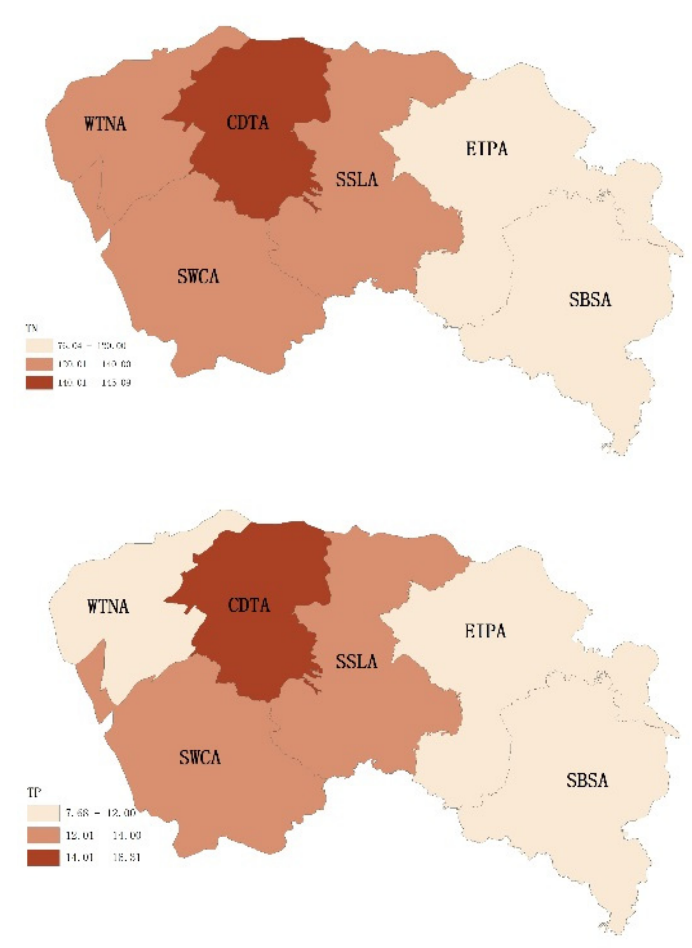

Figure 2. Pollution export fluxes of COD, SS, TN and TP in the six districts of the Dongguan city $\left(\mathrm{kg} / \mathrm{hm}^{2} \cdot \mathrm{a}\right)$.

In the context of the industrial and land use structure, the SSLA had the highest total annual loads (Table 2) probably because of the distributed paper products and textile industries. The CDTA had the highest pollution export fluxes (i.e. 2124, 3450, 145 and $16 \mathrm{~kg} / \mathrm{hm} 2 \cdot \mathrm{a}$ for COD, SS, TN and TP, respectively) (Figure 2), which indicated that the gaining commercial and residential areas had produce great amount of domestic sewage. The export fluxes were relatively lower in the Southeastern Bordering Shenzhen Area (i.e. 938, 1980, 76 and 8 $\mathrm{kg} / \mathrm{hm} 2 \cdot \mathrm{a}$ for COD, SS, TN and TP, respectively).

\section{Conclusions}

The annual runoff pollution loads export from the Dongguan city in 2020 were estimated in this study. The results showed that the total pollution loads of COD, SS, TN, and TP were 338489, 613175, 28292 and 2824 t/a, respectively. The SSLA had the highest annual loads of the four pollutants and the CDTA had the highest pollution export fluxes. It is crucial to enhance the environmental management in order to mitigate the runoff pollution in the study area. Improving the public environmental protection awareness is also necessary for maintaining water quality. The results of runoff pollution load in this research can provide some information of pollution status and trends, which is important for the regional water management and plans. 


\section{Acknowledgments}

This work was financially supported by the National Key R \& D Program of China (No. 2017YFC0405900), National Natural Science Foundation of China (Nos. 51809045 and 41801203), Natural Science Foundation for Distinguished Young Scholars of Guangdong Province (No. 2017A030306032), the Academician Workstation Project of Dongguan (No. DGYSZ201806), and the Scientific Research Foundation for High-level Talents and Innovation Team in Dongguan University of Technology (No. KCYKYQD2016001).

\section{References}

1. Qiu, S., Yin, H. W., Deng, J. L., et al. M. H. (2020) Cost-effectiveness analysis of green-gray stormwater control measures for non-point source pollution. International Journal of Environmental Research and Public Health. 17 (998). DOI: 10.3390/ijerph 17030998.

2. Zhang, X. Y., Zhi, X. S., Chen, L., et al. (2020) Spatiotemporal variability and key influencing factors of river fecal coliform within a typical complex watershed. Water Research. 178 (115835). DOI: 10.1016/j.watres.2020.115835.

3. Li, X. H., Zheng, X. K., Zhao, F., et al. (2017) Effects of urban non-point source pollution from Baoding City on Baiyangdian Lake, China. Water. 9 (249). DOI: $10.3390 /$ w9040249.

4. Li, J. K., Zhang, B., Li, Y. J., et al. (2018) Simulation of rain garden effects in urbanized area based on Mike Flood. Water. 10 (860). DOI: 10.3390/w10070860.

5. Liu, M., Li, C. L., Hu, Y. M., et al. (2014) Combining CLUE-S and SWAT models to forecast land use change and non-point source pollution impact at a watershed scale in Liaoning Province, China. Chinese Geographical Science. 24 (5): p. 540-550. DOI: 10.1007/s11769-014-0661-x.

6. Candela, A., Freni, G., Mannina, G., et al. (2012) Receiving water body quality assessment: an integrated mathematical approach applied to an Italian case study. Journal of Hydroinformatics. 14 (1): p. 30-47. DOI: 10.2166/hydro.2011.099.

7. Wang, S. R., Rao, P. Z., Yang, D. W., et al. (2020) A Combination model for quantifying non-point source pollution based on land use type in a typical urbanized area. Water. 12 (729). DOI: 10.3390/w12030729.

8. Akan, A. O.. (1993) Urban stormwater hydrology. USA: Technomic Publishing Company Inc. ISBN: 9780877629672.

9. Chen, K. L., Zhu, X. D., Wang, J. K., et al. (2007) Water pollution load in coastal zone of Xiamen: estimation and forecast. Chinese Journal of Applied Ecology. 18 (9): p. 2091-2096 (In Chinese).

10. Ma, Y., Ma, Y. W., Wan, J. Q., et al. (2011) Characterization of rainfall runoff pollution transportation in different underlying surface of Dongguan City. China Environmental Science. 31
(12): p. 1983-1990. DOI: CNKI: SUN: ZGHJ.0.201112-009 (In Chinese).

11. Bai, F. J., Li, T. H.. (2012) GIS and L-THIA Based Analysis on Variations of Non-point Pollution in the Guanlan River Watershed, Shenzhen. Environmental Science. 33 (8): p. 2667-2673. DOI: 10.13227/j.hjkx.2012.08.015 (In Chinese). 